\title{
Characterization of Clinical and Genetic Risk Factors Associated with Dyslipidemia after Kidney Transplantation
}

\author{
Kazuyuki Numakura, ${ }^{1}$ Hideaki Kagaya, ${ }^{2}$ Ryohei Yamamoto, ${ }^{1}$ \\ Naoki Komine, ${ }^{1}$ Mitsuru Saito, ${ }^{1}$ Tsuruta Hiroshi, ${ }^{1}$ Susumu Akihama, ${ }^{1}$ \\ Takamitsu Inoue, ${ }^{1}$ Shintaro Narita, ${ }^{1}$ Norihiko Tsuchiya, ${ }^{1}$ Tomonori Habuchi, ${ }^{1}$ \\ Takenori Niioka, ${ }^{2}$ Masatomo Miura, ${ }^{2}$ and Shigeru Satoh ${ }^{3}$ \\ ${ }^{1}$ Department of Urology, Akita University Graduate School of Medicine, Akita 010-8543, Japan \\ ${ }^{2}$ Department of Pharmacy, Akita University Hospital, Akita 010-8543, Japan \\ ${ }^{3}$ Center for Kidney Disease and Transplantation, Akita University Hospital, Akita 010-8543, Japan
}

Correspondence should be addressed to Kazuyuki Numakura; nqf38647@nifty.com

Received 31 December 2014; Accepted 26 March 2015

Academic Editor: Mariann Harangi

Copyright (C) 2015 Kazuyuki Numakura et al. This is an open access article distributed under the Creative Commons Attribution License, which permits unrestricted use, distribution, and reproduction in any medium, provided the original work is properly cited.

We determined the prevalence of dyslipidemia in a Japanese cohort of renal allograft recipients and investigated clinical and genetic characteristics associated with having the disease. In total, 126 patients that received renal allograft transplants between February 2002 and August 2011 were studied, of which 44 recipients (34.9\%) were diagnosed with dyslipidemia at 1 year after transplantation. Three clinical factors were associated with a risk of having dyslipidemia: a higher prevalence of disease observed among female than male patients $(P=0.021)$ and treatment with high mycophenolate mofetil $(P=0.012)$ and prednisolone $(P=0.023)$ doses per body weight at 28 days after transplantation. The genetic association between dyslipidemia and 60 previously described genetic polymorphisms in 38 putative disease-associated genes was analyzed. The frequency of dyslipidemia was significantly higher in patients with the glucocorticoid receptor $(N R 3 C 1) B c l 1 \mathrm{G}$ allele than in those with the CC genotype $(P=0.001)$. A multivariate analysis revealed that the $N R 3 C 1 B c l 1 \mathrm{G}$ allele was a significant risk factor for the prevalence of dyslipidemia (odds ratio $=4.6$; $95 \%$ confidence interval $=1.8-12.2$ ). These findings may aid in predicting a patient's risk of developing dyslipidemia.

\section{Introduction}

Dyslipidemia is a disorder of lipid metabolism and is characterized by elevated levels of lipid in the bloodstream. It is frequently observed in renal transplant recipients [1] and is a risk factor for cardiovascular disease and graft loss [2]. Prior to current immunosuppressive practices, the prevalence of dyslipidemia in renal transplant recipients was over $80 \%$ [3]; however, despite new interventions, the risk of disease remains at $44 \%$ to $60 \%$ [4]. There are a number of previously described risk factors for the development of dyslipidemia in renal transplant recipients, including diet and age; however, a number of therapeutic interventions associated with the transplantation, including steroid, cyclosporine (CyA), and mTOR inhibitor treatments, increase the risk of developing dyslipidemia [5].
Steroids influence cholesterol metabolism by activating acetyl-CoA carboxylase, hydroxymethylglutaryl-CoA reductase, and free fatty acid synthase, decreasing the activity of the low-density lipoprotein (LDL) receptor, and inhibiting lipoprotein lipase [6]. Consequently, steroid-based treatments such as steroid pulse therapy result in an increase of very low-density lipoproteins (VLDL), total cholesterol (TC), and triglyceride (TG) and a decrease of high-density lipoprotein (HDL). To avoid this, an early reduction in steroid treatment has been shown to reduce the incidence of dyslipidemia [7]. CyA is administered to transplant recipients to minimize graft rejection by inhibiting the growth and action of $\mathrm{T}$ cells. It has also been shown to inhibit 26-hydroxylase, a key enzyme involved in bile acid synthesis, which results in a decrease of cholesterol secretion into the intestine and 
a development of dyslipidemia [8]. Tacrolimus (TAC), a calcineurin inhibitor, reduces the incidence of dyslipidemia more than CyA (CyA, 36\% versus TAC, 26\%) [9]. Treatment with steroids and CyA has a synergistic effect that results in an increase in TC levels [10]. mTOR inhibitors, which are also commonly administered as an immunosuppressant, increase both TC and TG levels and inhibit the metabolism of apolipoprotein B100 in a dose-dependent manner. Inhibition of mTOR leads to a reduction in insulin secretion and insulinlike growth factor, which results in an increase in lipid synthesis within liver cells [11].

Since 1998, renal transplant recipients at our institute, who were all Japanese, have been treated under the same TAC-based immunosuppressive regimen. As is well known, there is marked individual diversity of blood TAC, mycophenolate mofetil (MMF), and steroid concentration after transplantation [12-14]. These genetic polymorphisms may influence individual variations in pharmacokinetics of immunosuppressive drugs. However, the association between drug pharmacokinetics and its related genetic polymorphisms with the prevalence of dyslipidemia under the TAC-based immunosuppression has not been definitively established.

The aim of this study was to determine the prevalence of dyslipidemia in a Japanese cohort and determine clinical and genetic characteristics associated with disease risk within the first year after transplantation under the TAC, MMF, and steroid therapy. A number of genetic polymorphisms that are associated with lipid metabolism have been previously described $[15,16]$. In this study, 60 polymorphisms in 38 genes known to be involved in lipid metabolism were examined to determine their association with the development of dyslipidemia.

\section{Materials and Methods}

2.1. Patients and Diagnosis of Dyslipidemia. One hundred and twenty-six adult patients who (i) received a renal allograft under TAC-based immunosuppression at Akita University Hospital between February 2002 and August 2011, (ii) had no serious complications, and (iii) maintained graft function for at least one year after transplantation were eligible for this study. From this patient cohort, individuals with high LDL cholesterol levels $(\geq 140 \mathrm{mg} / \mathrm{dL}$ ), hypertriglyceridemia ( $\geq \mathrm{TG}$ $150 \mathrm{mg} / \mathrm{dL})$, and low HDL cholesterol levels $(<40 \mathrm{mg} / \mathrm{dL})$ in the first year after transplantation, or those who required oral statin treatment, were defined as having dyslipidemia.

2.2. Immunosuppressive Therapy. Patients initially received combination immunosuppressive therapy consisting of TAC, MMF, and steroid. An initial oral dose $(0.15 \mathrm{mg} / \mathrm{kg})$ of TAC and 1.5-2.0 g/day of MMF were administered in two equally divided doses every $12 \mathrm{~h}$ at a designated time (09:00 and 21:00). The daily TAC dose was adjusted to achieve a whole blood trough level as previously reported [17]. Methylprednisolone was given concomitantly; a dose of $500 \mathrm{mg}$ on the day of surgery was initially administered and was subsequently tapered to $40 \mathrm{mg}$ /day during the first week, $20 \mathrm{mg} /$ day of prednisolone in the second week, $15 \mathrm{mg}$ /day of prednisolone in the third week, and $10 \mathrm{mg} /$ day thereafter. In the maintenance stage, the dose of prednisolone ranged from 2.5 to $10.0 \mathrm{mg}$ /day based on the immunosuppressive state of each patient. After July 2004, all patients received basiliximab $(20 \mathrm{mg}$ ) intravenously on the day of surgery and on postoperative day 4. Patients that were $\mathrm{ABO}$-incompatible or were receiving a second transplantation initially received MMF starting in 21 days and TAC and steroids starting 7 days prior to surgery. These patients either underwent a splenectomy at the time of transplantation or were administered rituximab (200 mg/body weight) intravenously (since 2005).

2.3. Evaluation of Renal Function. Renal function was evaluated based on the estimated glomerular filtration rate (eGFR). The eGFR was calculated using the following equation established for the Japanese population:

$$
\begin{aligned}
\operatorname{eGFR}\left(\mathrm{mL} / \mathrm{min} / 1.732 \mathrm{~m}^{2}\right) \\
=194 \times \text { Serum creatinine } \mathrm{C}^{-1.094} \\
\quad \times \text { Age }^{-0.287} \times 0.739(\text { if female }) .
\end{aligned}
$$

2.4. Evaluation of the Pharmacokinetic Profiles of TAC, MMF, and Steroid. On day 28 after renal transplantation, the whole blood samples were collected immediately prior to and 1 , $2,3,6,9$, and $12 \mathrm{~h}$ after the morning oral administration of TAC, MMF, and steroid. The concentration of TAC in the blood samples was measured by a microparticle enzyme immunoassay (IMx Abbott Laboratories, Abott Park, IL) performed in duplicate, and the concentration of mycophenolic acid, which is active metabolite of MMF, was measured by high-performance liquid chromatography. Pharmacokinetic analysis of prednisolone was carried out with a standard noncompartmental method using WinNonlin (Pharsight Co., Mountain View, CA, USA, version 4.0.1). The pharmacokinetics was estimated as previously reported $[12,17]$.

2.5. Genotyping of Genomic Polymorphisms. DNA was extracted from a peripheral blood sample using QIAamp Blood kit (Qiagen, Hilden, Germany) and was stored at $-4^{\circ} \mathrm{C}$ until analysis. Primer sequences and polymerase chain reaction (PCR) conditions for the analysis of each polymorphism were performed according to previous reports [12, 18-29]. All polymorphisms were analyzed by the PCR-restriction fragment length polymorphism (RFLP) method.

2.6. Statistical Analysis. Chi-square tests were used to test categorical data, whereas Mann-Whitney $U$ tests were employed to analyze continuous values between groups. $P$ values less than 0.05 were considered to be statistically significant. A logistic regression analysis was used to perform multivariate analyses. Clinical and genetic variables were included in the multivariate analyses if their univariate $P$ value was less than 0.10 . The analysis was performed using SPSS version 19.0 statistical software (SPSS Japan Inc., Tokyo, Japan). To test the population homogeneity of the subjects, the genotype 
TABLE 1: Comparison of clinical characteristics between patients with dyslipidemia and without dyslipidemia.

\begin{tabular}{lccc}
\hline & With dyslipidemia $(n=44)$ & Without dyslipidemia $(n=82)$ & \\
\hline At transplantation & & & \\
Age (yrs) & $49.2 \pm 10.3$ & $46.3 \pm 12.8$ & 0.205 \\
Gender (male : female) & $21: 23$ & $22.6 \pm 4.0$ & 0.021 \\
BMI $\left(\mathrm{kg} / \mathrm{m}^{2}\right)$ & $22.0 \pm 3.5$ & $49.0 \pm 73.9$ & 0.421 \\
Dialysis duration (mos) & $47.9 \pm 54.6$ & $58.4 \pm 10.1$ & 0.936 \\
Donor age (yrs) & $55.7 \pm 12.7$ & 16 & 0.219 \\
ABO incompatible & 16 & 2 & 0.162 \\
HCV antibody positive & 1 & 16 & 0.970 \\
yr after transplantation & & 30 & \\
CMV infection & 11 & 22 & 0.700 \\
Acute rejection & 17 & 62 & 0.951 \\
DM & 13 & 40 & 0.777 \\
Hypertension & 32 & $51.0 \pm 14.7$ \\
Hyperuricemia & 18 & 0.773 \\
eGFR & $54.1 \pm 14.1$ & 0.354 \\
\hline
\end{tabular}

Chi-square tests were used to test categorical data, whereas Mann-Whitney $U$ tests were employed to analyze continuous values between groups. $P$ values less than 0.05 were considered to be statistically significant.

Values are expressed as mean $\pm \mathrm{SD}$.

BMI, body mass index; eGFR, estimated glomerular filtration rate; $\mathrm{HCV}$, hepatitis C virus; CMV, cytomegalovirus; DM, diabetes mellitus.

frequencies of each polymorphism were tested against the Hardy-Weinberg equilibrium using a chi-square test.

\section{Results}

3.1. Patient Characteristics and Clinical Factors. The mean age of the transplant recipients at the time of transplantation was 47.3 years (range, 21-70 years), the dialysis duration was 48.6 months with a range of $0-420$ months, and the mean posttransplant follow-up period was 47.5 months (range, 10-125 months). The primary renal diseases among the patient cohort were chronic glomerulonephritis, including IgA nephropathy $(n=50)$, diabetes nephropathy $(n=15)$, polycystic kidney disease $(n=8)$, pregnancy toxicosis $(n=$ $5)$, reflux nephropathy $(n=5)$, nephrosclerosis $(n=3)$, lupus nephritis $(n=3)$, and nephrosclerosis $(n=2)$. Four cases were defined as "other," and 31 cases were uncharacterized.

Within the first year after transplantation, 44 patients $(34.9 \%)$ were diagnosed with dyslipidemia. The clinical characteristics of patients with and without dyslipidemia are summarized in Table 1. Females had a significantly higher prevalence of dyslipidemia over male patients. There were no significant differences in other clinical factors, including the mean body mass index, dialysis duration prior to transplantation, and eGFR at 1 year after transplantation.

3.2. Pharmacokinetics of TAC, MMF, and Steroid. An analysis of the pharmacokinetics of the immunosuppressive drugs revealed that the dose per body weight of MMF and steroid was higher in the transplant recipients with dyslipidemia than in patients without the disease at 28 days after transplantation ( $25.9 \pm 7.1$ versus $22.3 \pm 6.9 ; P=0.012,0.20 \pm 0.05$ versus 0.019 $\pm 0.03 ; P=0.023$, resp.) (Table 2).
3.3. Genetic Associations with Dyslipidemia. The association between having dyslipidemia and 60 polymorphisms in 38 genes was analyzed. These genes included known mediators of lipid metabolism (12 polymorphisms in 9 genes), cytokines (16 polymorphisms in 10 genes), and drug metabolism (32 polymorphisms in 19 genes). In seventeen polymorphisms, there were no variant alleles in this population (Table 3 ). The genotype frequencies at the glucocorticoid receptor (NR3C1) Bcll loci were 78 CC (61.9\%), 45 CG (35.7\%), and $3 G G$ (2.4\%). Patients with dyslipidemia had a significantly higher frequency of the $\mathrm{NR} 3 \mathrm{Cl} B c l 1 \mathrm{G}$ allele (dyslipidemia, 25, nondyslipidemia, 23) than in those with the $C C$ genotype (dyslipidemia, 19, nondyslipidemia, 59) $(P=0.001)$ (Table 3).

3.4. Multivariate Analysis. In the univariate analysis, female gender, dose per body weight of steroid and MMF, and NR3C1 Bcll $G$ allele were associated with dyslipidemia. Multivariate analyses of the genotype data further supported the correlation of the presence of the NR3C1 Bcll G allele (odds ratio, 4.671, $P=0.025$ ) with dyslipidemia (Table 4 ).

\section{Discussion}

The prevalence of dyslipidemia in renal transplant recipients is highly variable, having been previously reported to range from $44 \%$ to $80 \%$ [1]. Such variations are thought to be due to differences in the background of the patients or differences in the diagnostic criteria used to define dyslipidemia. Diagnosis of dyslipidemia has traditionally been based on TC, LDL and HDL cholesterol, and TG levels. However, TC levels are not associated with an increased risk of cardiovascular disease in the Japanese population, and therefore, LDL, HDL, and TG levels but not TC values are used as diagnostic criteria in Japan [30]. Given that the criteria may be different among 
TABLE 2: Comparison of pharmacokinetic parameters (TAC, MMF, and steroid) between patients with and without dyslipidemia.

\begin{tabular}{|c|c|c|c|c|}
\hline \multirow{2}{*}{ Drug } & \multirow{2}{*}{ Parameters } & \multicolumn{2}{|c|}{ After one month } & \multirow{2}{*}{$P$} \\
\hline & & With dyslipidemia & Without dyslipidemia & \\
\hline \multirow{4}{*}{ TAC } & Dose/BW (mg/kg/day) & $0.17 \pm 0.08$ & $0.20 \pm 0.10$ & 0.679 \\
\hline & $\mathrm{AUC}_{0-12}(\mathrm{ng} \cdot \mathrm{hr} / \mathrm{mL})$ & $170.0 \pm 34.6$ & $187.4 \pm 46.3$ & 0.457 \\
\hline & $C_{\max }(\mathrm{ng} / \mathrm{mL})$ & $18.6 \pm 4.7$ & $21.1 \pm 6.7$ & 0.166 \\
\hline & Trough & $9.2 \pm 3.2$ & $9.9 \pm 3.3$ & 0.518 \\
\hline \multirow{4}{*}{ MMF } & Dose/BW (mg/kg/day) & $25.9 \pm 7.1$ & $22.3 \pm 6.9$ & 0.012 \\
\hline & $\mathrm{AUC}_{0-12}(\mathrm{ng} \cdot \mathrm{hr} / \mathrm{mL})$ & $46.0 \pm 26.8$ & $46.2 \pm 18.7$ & 0.611 \\
\hline & $C_{\max }(\mathrm{ng} / \mathrm{mL})$ & $9.3 \pm 5.5$ & $9.0 \pm 4.9$ & 0.716 \\
\hline & Trough & $3.9 \pm 2.3$ & $2.8 \pm 1.7$ & 0.192 \\
\hline \multirow{4}{*}{ Steroid } & Dose/BW (mg/kg/day) & $0.20 \pm 0.05$ & $0.19 \pm 0.03$ & 0.023 \\
\hline & $\mathrm{AUC}_{0-24}(\mathrm{ng} \cdot \mathrm{hr} / \mathrm{mL})$ & $1051.1 \pm 426.9$ & $1059.1 \pm 407.4$ & 0.936 \\
\hline & $C_{\max }(\mathrm{ng} / \mathrm{mL})$ & $130.9 \pm 45.9$ & $141.3 \pm 46.5$ & 0.375 \\
\hline & Trough & $0.9 \pm 2.6$ & $2.4 \pm 8.5$ & 0.549 \\
\hline
\end{tabular}

Mann-Whitney $U$ tests were employed to analyze continuous values between groups.

$P$ values less than 0.05 were considered to be statistically significant.

Values are expressed as mean \pm SD.

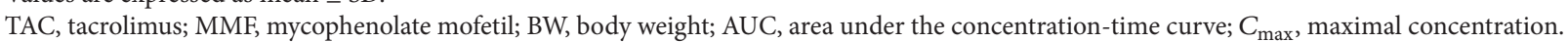

previous reports, careful consideration is needed when results are compared among studies [31].

Improvement in the diagnosis of dyslipidemia will ultimately rely on a unified set of diagnostic criteria to evaluate the presence of the disease. After kidney transplantation, the prevalence of dyslipidemia has been demonstrated to increase over time [5]. However, in somewhat of disagreement, a second study reported that the rate of dyslipidemia decreased after one year after transplantation [32]. These two studies highlight the importance of carefully considering the diagnostic criteria and timeframe in which the evaluation takes place. In this study, patients that presented with LDL cholesterol levels above $140 \mathrm{mg} / \mathrm{dL}$, TC levels above $150 \mathrm{mg} / \mathrm{dL}$, and HDL cholesterol levels below $40 \mathrm{mg} / \mathrm{dL}$ in the first year after transplantation, or patients requiring the administration of an oral statin, were diagnosed as having dyslipidemia [30]. Using these criteria, the prevalence of dyslipidemia was found to be $34.9 \%$.

Genetic polymorphisms have been previously investigated in association with renal transplantation, including the development of secondary complications such as diabetes [25] and hyperuricemia [33], as well as their role in the metabolism of immunosuppressive drugs [14]. In multifactorial diseases such as dyslipidemia, genetic polymorphism in genes associated with the disease likely influences the susceptibility towards disease progression. Understanding the association between such polymorphism and the disease could lead to the implementation of genetic tests that predict the risk of developing the disease $[25,33]$. In this study, 60 polymorphisms in 38 genes were examined, from which the frequency of the $\mathrm{G}$ allele in the $\mathrm{NR} 3 \mathrm{Cl} \mathrm{Bcl}$ l gene was found to be higher in patients with dyslipidemia. The glucocorticoid receptor, which is also known as nuclear receptor subfamily 3 , group $\mathrm{C}$, member $1(\mathrm{NR} 3 \mathrm{Cl})$, is a main regulatory receptor at the hypothalamic-pituitary-adrenal axis. Glucocorticoids regulate the release of glucose from cells in order to supply the body response to face environmental stress. They also induce insulin resistance directly by perturbing insulin signal transduction via glucocorticoid receptor and indirectly by promoting visceral fat deposition and loss of lean mass [34]. In the NR3C1 Bcl1 $G$ allele carriers, variation in this receptor was associated with obesity, hypertension, and diabetes [35, 36]. Additionally, NR3C1 Bcl1 GG genotype was significantly associated with an increased risk of metabolic syndrome and high BMI in Chinese population [37, 38]. It is possible that increased sensitivity of the glucocorticoid receptor [39] has an influence on the development of dyslipidemia [40]; nevertheless, no difference was observed in the steroid pharmacokinetics. Although a level of significance was achieved, the genetic analysis should be interpreted with caution. When multiple testing parameters are taken into account by applying Bonferroni correction (adjusted $P$ value $<0.0008$ based on 60 single nucleotide polymorphisms analyzed), none of the polymorphisms reached a level of statistical significance. This is not necessarily surprising, given that the study was performed retrospectively and made use of limited patient data and samples that were available. Future studies with a greater number of patients with predefined disease criteria will be important in determining the association of this polymorphism with dyslipidemia.

Apart from the NR3C1 Bcl1 G allele, a number of predicted risk factors that were initially identified in the univariate analysis were not significantly associated with dyslipidemia when analyzed by multivariate analysis. It is likely that the gender of the patient would have been a confounding factor of the dose of immunosuppressive drugs administered; as pharmacokinetic monitoring of steroids and MMF is not common practice, a fixed dose was administered to all renal transplant recipients regardless of gender or body weight. Consequently, a larger dose per body weight of steroid and MMF would have been administered to women. Conversely, the fact that the area under the concentration, which was 
TABLE 3: Association of pharmacokinetics, cytokines, and dyslipidemia-related polymorphisms.

\begin{tabular}{|c|c|c|c|c|c|c|}
\hline Number & Gene & Polymorphisms & Categories & OR & $95 \% \mathrm{CI}$ & $P$ \\
\hline 1 & IL-2 & $T-330 G$ & G allele & 0.482 & $0.157-1.480$ & 0.200 \\
\hline 2 & IL-2R $\beta$ & $C-627 T$ & Tallele & 0.591 & $0.187-1.867$ & 0.545 \\
\hline 3 & IL-4 & C-590T & TT genotype & 0.952 & $0.316-2.873$ & 0.931 \\
\hline 4 & IL-10 & $A-592 C$ & Callele & 0.912 & $0.299-2.784$ & 0.872 \\
\hline 5 & IL-12B & A1188C & $C$ allele & 1.156 & $0.272-4.905$ & 0.861 \\
\hline \multirow[t]{2}{*}{6} & TNF- $\alpha$ & $G-238 A$ & $A$ allele & - & - & 1.000 \\
\hline & & $G-308 A$ & $A$ allele & - & - & 1.000 \\
\hline 7 & INF $\gamma$ & $A 874 T$ & Tallele & - & - & 1.000 \\
\hline \multirow[t]{3}{*}{8} & TGF- $\beta 1$ & Codon $10 \mathrm{~T} / \mathrm{C}$ & CC genotype & 1.225 & $0.322-4.667$ & 0.964 \\
\hline & & Codon $25 \mathrm{G} / \mathrm{C}$ & $C$ allele & - & - & 1.000 \\
\hline & & C-509T & TT genotype & 0.719 & $0.203-2.543$ & 0.844 \\
\hline \multirow[t]{4}{*}{9} & CRP & $T-717 C$ & $C$ allele & 1.474 & $0.268-8.092$ & 0.993 \\
\hline & & G1059C & $C$ allele & 2.289 & $0.349-15.010$ & 0.686 \\
\hline & & C1444T & T allele & 0.926 & $0.228-3.765$ & 0.804 \\
\hline & & C1846T & TT genotype & 1.067 & $0.358-3.182$ & 0.908 \\
\hline \multirow[t]{2}{*}{10} & HNF1 $\alpha$ & Ileu27Leu & Leu/Leu genotype & 0.857 & $0.318-2.310$ & 0.760 \\
\hline & & Ala98Val & Val allele & - & - & 1.000 \\
\hline \multirow[t]{2}{*}{11} & Adiponectin & T45G & $G$ allele & 2.000 & $0.659-6.066$ & 0.341 \\
\hline & & G276T & T allele & 0.889 & $0.236-3.351$ & 0.869 \\
\hline 12 & $\operatorname{PPAR} \alpha$ & Val227Ala & Ala allele & - & - & 1.000 \\
\hline \multirow[t]{2}{*}{13} & $\operatorname{PPAR} \gamma$ & Pro12Ala & Ala allele & 2.000 & $0.115-34.824$ & 0.866 \\
\hline & & C161T & T allele & 2.036 & $0.518-7.995$ & 0.565 \\
\hline \multirow[t]{2}{*}{14} & PPAR $\gamma$ coactivator 1 & Gly482Ser & Ser/ser genotype & 3.250 & $0.480-21.998$ & 0.438 \\
\hline & & G394A & $A$ allele & 0.381 & $0.073-1.992$ & 0.449 \\
\hline 15 & Clock gene & T3111C & $C$ allele & - & - & 0.876 \\
\hline 16 & $\mathrm{ACE}$ & $\mathrm{I} / \mathrm{D}$ & Deletion & 1.270 & $0.381-4.230$ & 0.697 \\
\hline 17 & ATIIR & A1166C & $C$ allele & 0.454 & $0.105-1.955$ & 0.464 \\
\hline 18 & KCNJ11 & E23K & $A$ allele & 0.571 & $0.185-1.765$ & 0.329 \\
\hline 19 & SUR1 & $C-3 T$ & TT genotype & 0.286 & $0.081-1.008$ & 0.946 \\
\hline 20 & UGT1A1 & Promoter TA-repeat & ${ }^{*} 6$ allele & 0.729 & $0.299-1.777$ & 0.486 \\
\hline 21 & UGT1A6* 2 & ${ }^{*} 1 /{ }^{*} 2$ & ${ }^{*} 2$ allele & 0.955 & $0.255-3.576$ & 0.789 \\
\hline 22 & UGT1A7 & Codon $208^{*} 1 /^{*} 3$ & ${ }^{*} 3$ allele & 1.280 & $0.228-7.187$ & 0.873 \\
\hline 23 & UGT1A $8 * 2$ & codon173 A/G & GG genotype & 1.176 & $0.507-2.732$ & 0.705 \\
\hline 24 & UGT1A $8 * 3$ & codon $277 \mathrm{C} / \mathrm{Y}$ & $Y$ allele & - & - & 1.000 \\
\hline \multirow[t]{3}{*}{25} & UGT1A9 & $C-2152 T$ & $T$ allele & - & - & 1.000 \\
\hline & & $T-275 A$ & $A$ allele & - & - & 1.000 \\
\hline & & C1399T & TT genotype & 1.126 & $0.485-2.617$ & 0.783 \\
\hline 26 & UGT1A9*3 & T98C & $C$ allele & - & - & 1.000 \\
\hline 27 & UGT2B7 & C802T & T allele & 0.770 & $0.330-1.795$ & 0.545 \\
\hline 28 & $\mathrm{CYP} 2 \mathrm{C} 9^{*} 2$ & C430T & Tallele & - & - & 1.000 \\
\hline 29 & СYP2C9*3 & A1075C & $C$ allele & 2.741 & $0.715-10.509$ & 0.242 \\
\hline 30 & CYP2C19 & ${ }^{*} 1 /^{*} 2 /^{*} 3$ & ${ }^{*} 2 /^{*} 2,{ }^{*} 2 /^{*} 3,{ }^{*} 3 /^{*} 3$ & 0.697 & $0.220-2.208$ & 0.739 \\
\hline \multirow[t]{2}{*}{31} & CYP3A4 & ${ }^{*} 1{ }^{*} 18$ & ${ }^{*} 18$ allele & - & - & 1.000 \\
\hline & & G20230A & $A$ allele & 0.551 & $0.235-1.294$ & 0.169 \\
\hline 32 & CYP3A5 & $A 6985 G$ & GG genotype & 1.815 & $0.773-4.263$ & 0.169 \\
\hline \multirow[t]{3}{*}{33} & MDR-1 & $C 1236 T$ & TT genotype & 1.067 & $0.291-3.916$ & 0.814 \\
\hline & & C3435T & T allele & 0.868 & $0.200-3.766$ & 0.850 \\
\hline & & $G 2677 T \cdot A$ & Tor A allele & 0.688 & $0.152-3.102$ & 0.922 \\
\hline
\end{tabular}


TABLE 3: Continued.

\begin{tabular}{|c|c|c|c|c|c|c|}
\hline Number & Gene & Polymorphisms & Categories & OR & $95 \% \mathrm{CI}$ & $P$ \\
\hline \multirow[t]{4}{*}{34} & OATP1B1 & A388G & GG genotype & 1.143 & $0.482-2.712$ & 0.762 \\
\hline & & G455A & A allele & - & - & 1.000 \\
\hline & & T521C & $C$ allele & 0.593 & $0.226-1.551$ & 0.284 \\
\hline & & G721A & A allele & - & - & 1.000 \\
\hline \multirow[t]{3}{*}{35} & OATP1B3 & $T 334 G$ & GG genotype & 1.176 & $0.507-2.732$ & 0.705 \\
\hline & & G699A & AA genotype & 0.714 & $0.242-2.108$ & 0.542 \\
\hline & & Deletion A & Deletion & 1.309 & $0.310-5.534$ & 0.714 \\
\hline 36 & OATP2B1 & ${ }^{*} 1 /{ }^{*} 3$ & ${ }^{*} 3$ allele & 0.936 & $0.402-2.176$ & 0.877 \\
\hline \multirow[t]{3}{*}{37} & Glucocorticoid receptor & $\mathrm{Bcl} I \mathrm{C} / \mathrm{G}$ & G allele & 3.375 & $1.568-7.266$ & 0.001 \\
\hline & & $E R 22 / 23 E K$ & EK allele & - & - & 1.000 \\
\hline & & N363S & S allele & - & - & 1.000 \\
\hline \multirow[t]{2}{*}{38} & CES2 & rs2303218 & AA genotype & 2.700 & $0.697-10.465$ & 0.146 \\
\hline & & $r s 3890213$ & A allele & 3.429 & $0.791-14.854$ & 0.190 \\
\hline
\end{tabular}

IL, interleukin; TNF, tumor necrosis factor; INF, interferon; TGF, transforming growth factor; CRP, C-reactive protein; HNF, hepatocyte nuclear factor; PPAR, peroxisome proliferator-activated receptor; ACE, angiotensin-converting enzyme; ATIIR, angiotensin type 2 receptor; KCNJ, potassium inwardly rectifying channel, subfamily J; SUR, sulfonylurea receptor; UGT, uridine diphosphate-glucuronosyltransferase; CYP, cytochrome P450; MDR, multidrug resistance; OATP, organic anion transporting polypeptide; CES, carboxylesterase; OR, odds ratio; CI, confidence interval.

TABLE 4: Multivariate analysis of risk factors for dyslipidemia.

\begin{tabular}{lccccr}
\hline \multirow{2}{*}{ Factors } & Categories & \multicolumn{2}{c}{ Univariate } & \multicolumn{2}{c}{ Multivariate } \\
& & OR & $P$ & OR & CI \\
\hline NR3C1 Bcl I & Gallele & 4.607 & 0.001 & 4.671 & $1.795-12.156$ \\
MMF/BW & $\geq 24.2$ & 2.902 & 0.027 & 2.212 & $0.771-6.350$ \\
Steroid/BW & $\geq 0.188$ & 2.526 & 0.034 & 1.126 & $0.389-3.256$ \\
Gender & Female & 2.494 & 0.021 & 1.779 & 0.375 \\
\hline
\end{tabular}

NR3C1, glucocorticoid receptor; BW, body weight; MMF, mycophenolate mofetil; OR, odds ratio; CI, confidence interval.

an effective pharmacokinetic marker of steroid and MMF treatment [41], was not found to be a significant factor in the multivariate analysis was quite reasonable.

\section{Conclusion}

The prevalence of dyslipidemia was found to be $34.9 \%$ in the Japanese cohort analyzed. The pharmacokinetics profiles of TAC, MMF, and steroid were not associated with the development of dyslipidemia under the same TAC-based immunosuppression treatment. However, the frequency of the NR3C1 Bcll G allele was found to be higher in patients having dyslipidemia and therefore may be a putative genetic marker for predicting risk of the disease. Although the mechanism by which the NR3C1 Bcl1 G allele might be involved in the prevalence of dyslipidemia is not clear, the analysis of dyslipidemia-related polymorphisms may provide a means to predict patient's risk for having dyslipidemia. Further studies with a larger number of subjects are needed to validate the genetic risk factors associated with the prevalence of dyslipidemia and, in particular, the association of NR3C1 Bcll genotypes.

\section{Conflict of Interests}

The authors declare that there is no conflict of interests regarding the publication of this paper.

\section{Acknowledgments}

The authors are grateful for the assistance of Mr. Fujiyama and Ms. Mitobe with the data collection.

\section{References}

[1] L. V. Riella, S. Gabardi, and A. Chandraker, "Dyslipidemia and its therapeutic challenges in renal transplantation," American Journal of Transplantation, vol. 12, no. 8, pp. 1975-1982, 2012.

[2] H. Holdaas, B. Fellström, E. Cole et al., "Long-term cardiac outcomes in renal transplant recipients receiving fluvastatin: the ALERT extension study," American Journal of Transplantation, vol. 5, no. 12, pp. 2929-2936, 2005.

[3] J. E. Gonyea and C. F. Anderson, "Weight change and serum lipoproteins in recipients of renal allografts," Mayo Clinic Proceedings, vol. 67, no. 7, pp. 653-657, 1992. 
[4] R. S. Gaston, B. L. Kasiske, A. M. Fieberg et al., "Use of cardioprotective medications in kidney transplant recipients," The American Journal of Transplantation, vol. 9, no. 8, pp. 1811$1815,2009$.

[5] B. Kasiske, F. G. Cosio, J. Beto et al., "Clinical practice guidelines for managing dyslipidemias in kidney transplant patients: a report from the Managing Dyslipidemias in Chronic Kidney Disease Work Group of the National Kidney Foundation Kidney Disease Outcomes Quality Initiative," American Journal of Transplantation, vol. 4, supplement 7, pp. 13-53, 2004.

[6] J. A. Kobashigawa and B. L. Kasiske, "Hyperlipidemia in solid organ transplantation," Transplantation, vol. 63, no. 3, pp. 331338, 1997.

[7] E. S. Woodle, M. R. First, J. Pirsch, F. Shihab, A. O. Gaber, and P. Van Veldhuisen, "A prospective, randomized, doubleblind, placebo-controlled multicenter trial comparing early (7 day) corticosteroid cessation versus long-term, low-dose corticosteroid therapy," Annals of Surgery, vol. 248, no. 4, pp. 564-577, 2008.

[8] K. Mizuta, E. Kobayashi, H. Uchida et al., "Dose-dependent reduction of bile secretion in cyclosporine-treated rats," Transplantation, vol. 65, no. 5, pp. 758-759, 1998.

[9] H. Ekberg, C. Bernasconi, H. Tedesco-Silva et al., "Calcineurin inhibitor minimization in the symphony study: observational results 3 years after transplantation," The American Journal of Transplantation, vol. 9, no. 8, pp. 1876-1885, 2009.

[10] D. E. Hricik, J. T. Mayes, and J. A. Schulak, "Independent effects of cyclosporine and prednisone on posttransplant hypercholesterolemia," The American Journal of Kidney Diseases, vol. 18, no. 3, pp. 353-358, 1991.

[11] B. L. Kasiske, A. de Mattos, S. M. Flechner et al., "Mammalian target of rapamycin inhibitor dyslipidemia in kidney transplant recipients," American Journal of Transplantation, vol. 8, no. 7, pp. 1384-1392, 2008.

[12] M. Miura, K. Inoue, H. Kagaya, M. Saito, T. Habuchi, and S. Satoh, "Inter-individual difference determinant of prednisolone pharmacokinetics for Japanese renal transplant recipients in the maintenance stage," Xenobiotica, vol. 39, no. 12, pp. 939-945, 2009.

[13] M. Miura, T. Niioka, S. Kato et al., "Monitoring of mycophenolic acid predose concentrations in the maintenance phase more than one year after renal transplantation," Therapeutic Drug Monitoring, vol. 33, no. 3, pp. 295-302, 2011.

[14] S. Satoh, M. Saito, T. Inoue et al., "CYP3A5*1 allele associated with tacrolimus trough concentrations but not subclinical acute rejection or chronic allograft nephropathy in Japanese renal transplant recipients," European Journal of Clinical Pharmacology, vol. 65, no. 5, pp. 473-481, 2009.

[15] O. Ukkola and C. Bouchard, "Clustering of metabolic abnormalities in obese individuals: the role of genetic factors," Annals of Medicine, vol. 33, no. 2, pp. 79-90, 2001.

[16] C. Baigent, L. Blackwell, J. Emberson et al., "Efficacy and safety of more intensive lowering of LDL cholesterol: a meta-analysis of data from 170,000 participants in 26 randomised trials," The Lancet, vol. 376, no. 9753, pp. 1670-1681, 2010.

[17] Y. Miura, S. Satoh, M. Saito et al., "Factors increasing quantitative interstitial fibrosis from 0 hr to 1 year in living kidney transplant patients receiving tacrolimus," Transplantation, vol. 91, no. 1, pp. 78-85, 2011.

[18] S. Motoyama, M. Miura, Y. Hinai et al., "CRP genetic polymorphism is associated with lymph node metastasis in thoracic esophageal squamous cell cancer," Annals of Surgical Oncology, vol. 16, no. 9, pp. 2479-2485, 2009.

[19] W. Winckler, N. P. Burtt, J. Holmkvist et al., "Association of common variation in the HNF1 $\alpha$ gene region with risk of type 2 diabetes," Diabetes, vol. 54, no. 8, pp. 2336-2342, 2005.

[20] S. Motoyama, M. Miura, Y. Hinai, K. Maruyama, K. Murata, and J.-I. Ogawa, "C-reactive protein $2717 \mathrm{C}>\mathrm{T}$ genetic polymorphism associates with esophagectomy-induced stress hyperglycemia," World Journal of Surgery, vol. 34, no. 5, pp. 1001-1007, 2010.

[21] T. Sato, M. Sato, M. Miura et al., "Expression of the Peroxisome Proliferator-Activated Receptors (PPARs) in the hepatic stellate cells," Comparative Hepatology, vol. 3, supplement 1, article S17, 2004.

[22] K. Tsuzaki, K. Kotani, Y. Sano, S. Fujiwara, K. Takahashi, and N. Sakane, "The association of the Clock 3111 T/C SNP with lipids and lipoproteins including small dense low-density lipoprotein: results from the Mima study," BMC Medical Genetics, vol. 11, no. 1, article 150, 2010.

[23] S. Takami, Y. Imai, T. Katsuya et al., "Gene polymorphism of the renin-angiotensin system associates with risk for lacunar infarction: the Ohasama study," The American Journal of Hypertension, vol. 13, no. 2, pp. 121-127, 2000.

[24] T. Yoshida, K. Kato, K. Yokoi et al., "Association of genetic variants with chronic kidney disease in individuals with different lipid profiles," International Journal of Molecular Medicine, vol. 24, no. 2, pp. 233-246, 2009.

[25] K. Numakura, S. Satoh, N. Tsuchiya et al., "Clinical and genetic risk factors for posttransplant diabetes mellitus in adult renal transplant recipients treated with tacrolimus," Transplantation, vol. 80, no. 10, pp. 1419-1424, 2005.

[26] M. Miura, H. Kagaya, S. Satoh et al., "Influence of drug transporters and UGT polymorphisms on pharmacokinetics of phenolic glucuronide metabolite of mycophenolic acid in Japanese renal transplant recipients," Therapeutic Drug Monitoring, vol. 30, no. 5, pp. 559-564, 2008.

[27] M. Miura, K. Otani, and T. Ohkubo, "Identification of human cytochrome P450 enzymes involved in the formation of 4hydroxyestazolam from estazolam," Xenobiotica, vol. 35 , no. 5, pp. 455-465, 2005.

[28] Y. Akamine, M. Miura, S. Sunagawa, H. Kagaya, N. YasuiFurukori, and T. Uno, "Influence of drug-transporter polymorphisms on the pharmacokinetics of fexofenadine enantiomers," Xenobiotica, vol. 40, no. 11, pp. 782-789, 2010.

[29] N. Fujiyama, M. Miura, S. Satoh et al., "Influence of carboxylesterase 2 genetic polymorphisms on mycophenolic acid pharmacokinetics in Japanese renal transplant recipients," Xenobiotica, vol. 39, no. 5, pp. 407-414, 2009.

[30] Japan Atherosclerosis Society, "Japan Atherosclerosis Society (JAS) guidelines for prevention of atherosclerotic cardiovascular diseases," Journal of Atherosclerosis and Thrombosis, pp. 5-57, 2007.

[31] E. Razeghi, M. Shafipour, H. Ashraf, and G. Pourmand, "Lipid disturbances before and after renal transplant," Experimental and Clinical Transplantation, vol. 9, no. 4, pp. 230-235, 2011.

[32] G. Raees-Jalali, A. Eshraghian, A. Faghihi et al., "Hyperlipidemia after kidney transplantation: long-term graft outcome," Iranian Journal of Kidney Diseases, vol. 6, no. 1, pp. 49-55, 2012.

[33] K. Numakura, S. Satoh, N. Tsuchiya et al., "Hyperuricemia at 1 year after renal transplantation, its prevalence, associated factors, and graft survival," Transplantation, vol. 94, no. 2, pp. 145-151, 2012. 
[34] N. Marissal-Arvy, A. Langlois, C. Tridon, and P. Mormede, "Functional variability in corticosteroid receptors is a major component of strain differences in fat deposition and metabolic consequences of enriched diets in rat," Metabolism: Clinical and Experimental, vol. 60, no. 5, pp. 706-719, 2011.

[35] N. Srivastava, J. Prakash, R. Lakhan, C. G. Agarwal, D. C. Pant, and B. Mittal, "Influence of Bcl-1 gene polymorphism of glucocorticoid receptor gene (NR3C1, rs41423247) on blood pressure, glucose in Northern Indians," Indian Journal of Clinical Biochemistry, vol. 26, no. 2, pp. 125-130, 2011.

[36] R. Rosmond and G. Holm, "A 5-year follow-up study of 3 polymorphisms in the human glucocorticoid receptor gene in relation to obesity, hypertension, and diabetes," Journal of the cardiometabolic syndrome, vol. 3, no. 3, pp. 132-135, 2008.

[37] Y. X. Yan, J. Dong, J. Zhang et al., "Polymorphisms in NR3C1 gene associated with risk of metabolic syndrome in a Chinese population," Endocrine, vol. 47, no. 3, pp. 740-748, 2014.

[38] Y.-X. Yan, J. Dong, L.-J. Wu et al., "Associations between polymorphisms in the glucocorticoid-receptor gene and cardiovascular risk factors in a chinese population," Journal of Epidemiology, vol. 23, no. 5, pp. 389-395, 2013.

[39] R. Rosmond, Y. C. Chagnon, G. Holm et al., "A glucocorticoid receptor gene marker is associated with abdominal obesity, leptin, and dysregulation of the hypothalamic-pituitary-adrenal axis," Obesity Research, vol. 8, no. 3, pp. 211-218, 2000.

[40] G. Zalewski, A. Wasilewska, W. Zoch-Zwierz, and L. Chyczewski, "Response to prednisone in relation to $\mathrm{NR} 3 \mathrm{C} 1$ intron B polymorphisms in childhood nephrotic syndrome," Pediatric Nephrology, vol. 23, no. 7, pp. 1073-1078, 2008.

[41] S. Satoh, H. Tada, M. Murakami et al., "Circadian pharmacokinetics of mycophenolic acid and implication of genetic polymorphisms for early clinical events in renal transplant recipients," Transplantation, vol. 82, no. 4, pp. 486-493, 2006. 


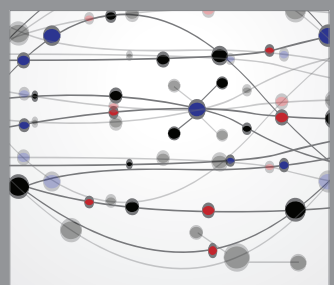

The Scientific World Journal
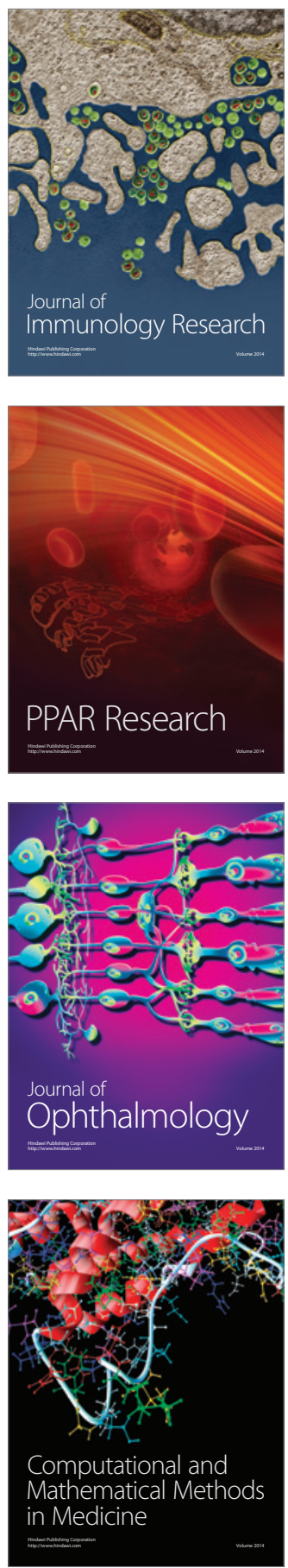

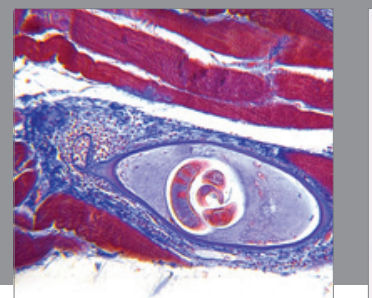

Gastroenterology

Research and Practice
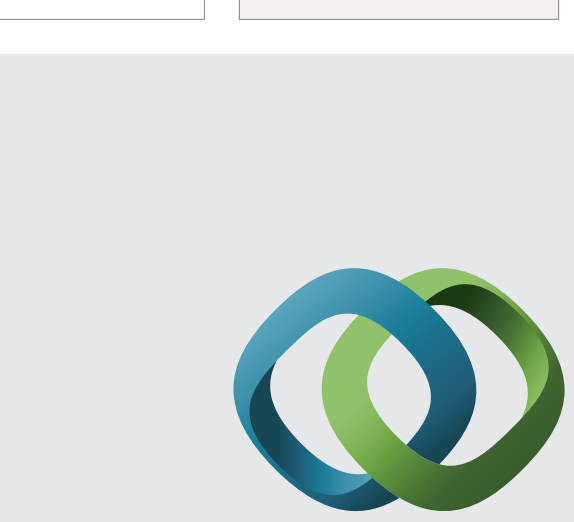

\section{Hindawi}

Submit your manuscripts at

http://www.hindawi.com
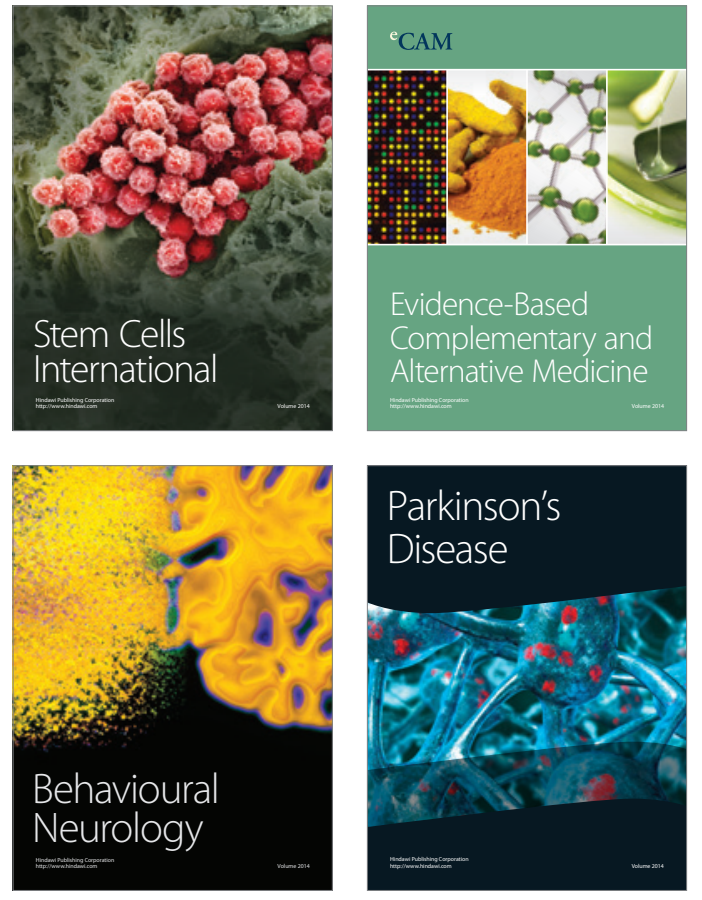
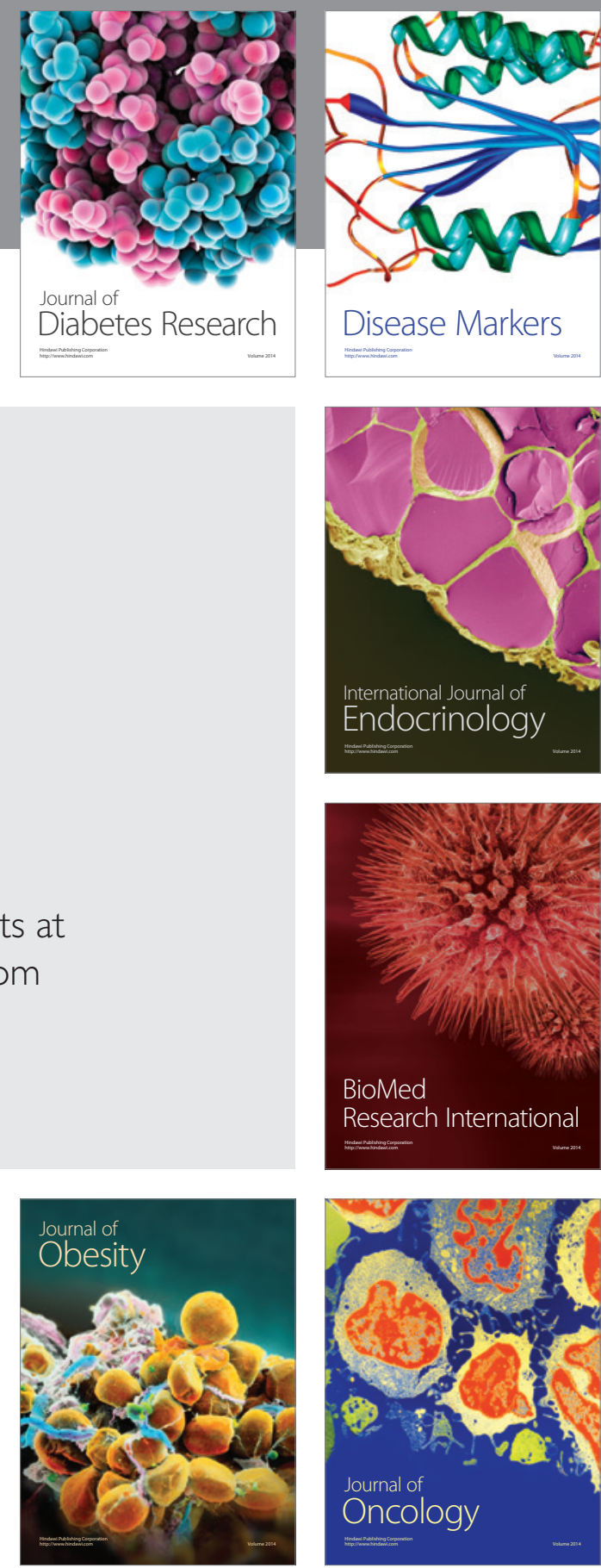

Disease Markers
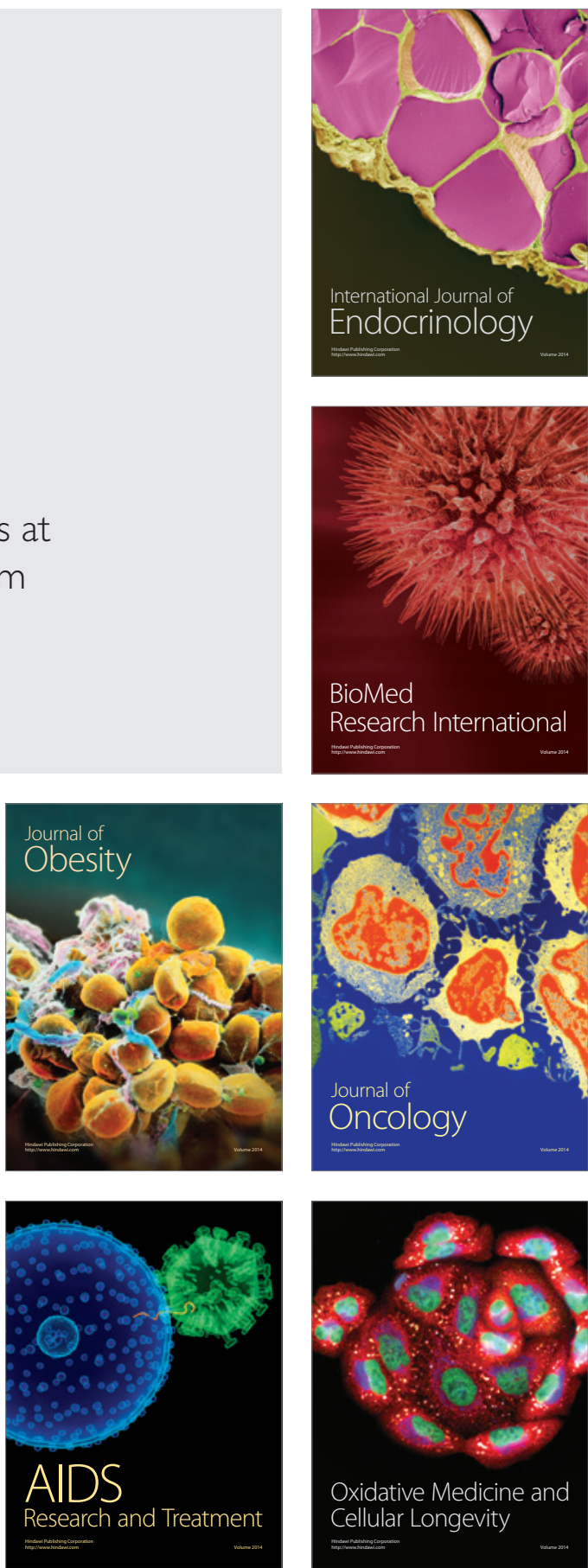